Revista Brasileira de Agricultura Irrigada v.12, nº.6, p. 3028 - 3039, 2018

ISSN 1982-7679 (On-line)

Fortaleza, CE, INOVAGRI - http://www.inovagri.org.br

DOI: $10.7127 /$ rbai.v12n600914

Protocolo 914.18 - 03/04/2018 Aprovado em 23/12/2018

\title{
PRODUTIVIDADE DE FEIJÃO-CAUPI SUBMETIDO A DIFERENTES LÂMINAS DE IRRIGAÇÃO COM USO DE BIOFERTILIZANTE
}

Weslley Costa Silva ${ }^{1}$, Joana Gomes de Moura ${ }^{2}$, Italo Emerson Trindade Viana ${ }^{3}$, André Luis da Silva Parente Nogueira ${ }^{4}$, Tatiana Maria da Silva ${ }^{5}$, Alexandre Bosco de Oliveira ${ }^{6 *}$

\section{RESUMO}

O feijão-caupi constitui-se em um dos principais componentes na alimentação da população no Nordeste brasileiro. Desta forma, objetivou-se com este trabalho avaliar a produtividade do feijão-caupi irrigado com diferentes lâminas e o uso de biofertilizante. O delineamento foi em blocos casualizados dispostos em parcelas subdivididas, sendo as parcelas constituídas por quatro lâminas de irrigação com água salina $(75,100,125$ e $150 \%$ da evapotranspiração da cultura - ETc) e as subparcelas a presença e ausência de biofertilizante. Aos 75 dias após a semeadura (DAS) realizou-se a colheita da cultura sendo análisadas as seguintes variáveis: número de vagens por planta, comprimento de vagem verde e seca, número e massa de grãos por vagem, massa de 100 grãos e produtividade. Aplicação de lâminas próximo a $125 \%$ da ETc provoca redução no comprimento média de vagem, massa de vagem verde e seca, massa de 100 grãos e produtividade do feijão-caupi. O uso de biofertilizante com lâminas de 75 e $100 \%$ da ETc reduz os valores dos componentes produtivos da cultura. O uso de biofertilizante apresenta resposta positiva com a lâmina de $150 \%$ da ETc, aumentando a massa de grãos verdes por vagem e massa de 100 grãos.

Palavras-chave: Vigna unguiculata (L.) Walp, disponibilidade hídrica , adubo orgânico

\section{PRODUCTIVITY OF COWPEA SUBMITTED TO DIFFERENT IRRIGATION BLADES WITH USE BIOFERTILIZER}

\footnotetext{
*Autor para correspondência

1 Doutorando em Agronomia/Fitotecnia, Universidade Federal do Ceará, Fortaleza, Brasil. E-mail: weslleyc.s@hotmail.com

2 Doutoranda em Agronomia, Universidade Federal da Paraíba, Areia, Brasil. E-mail: joanagomes1963@hotmail.com

3 Graduando em Agronomia, Universidade Federal do Ceará, Fortaleza, Brasil. E-mail: italovians @ gmail.com

4 Mestrando em Solos e Nutrição de Plantas, Universidade Federal do Ceará, Fortaleza, Brasil. Email: parentenogueira@hotmail.com

5 Doutora em Agronomia/Fitotecnia, Universidade Federal do Ceará, Fortaleza, Brasil. E-mail: tatianad.silva@hotmail.com

6 Doutor e Professor do Departamento de Fitotecnia, Universidade Federal do Ceará, Fortaleza, Brasil. Email: alexandrebosco@ufc.br
} 


\begin{abstract}
The cowpea is one of the main components in the population diet in the northeast of Brazil. The objective of this work was to evaluate the productivity of irrigated cowpea with different slides and the use of biofertilizer. The randomized block design, using a scheme of split lots consisting of four irrigation depths with saline water $(75,100,125$ and $150 \%$ of crop evapotranspiration - ETc) and sub-lots the presence and absence of biofertilizer. At 75 days after sowing (DAS) the culture was harvested and the following variables were analyzed: number of pods per plant, green and dry pod length, number and mass of grains per pod, mass of 100 grains and yield. Application of slides above $125 \%$ of ETc leads to reduction in mean pod length, green and dry pod mass, 100 grain mass and cowpea productivity. The use of biofertilizer with 75 and $100 \%$ ETc slides reduces the values of the productive components of the crop. The use of biofertilizer has a positive response with the 150\% ETc blade, increasing the mass of green grains per pod and mass of 100 grains.
\end{abstract}

Keywords: Vigna unguiculata (L.) Walp, water availability, organic fertilizer

\section{INTRODUÇÃO}

O feijão-caupi [Vigna unguiculata (L.) Walp] é uma Fabaceae de considerável importância nas regiões tropicais e subtropicais do mundo (SALVADOR, 2010). Tradicionalmente produzida por pequenos agricultores no Nordeste do Brasil, na última década seu cultivo vêm expandindo-se para outras regiões brasileiras, principalmente para o Centro-Oeste (FREIRE FILHO et al., 2011).

Apesar da sua boa adaptabilidade a condições adversas, para que a cultura produza satisfatoriamente, deve-se disponibilizar água em quantidade adequada, sendo este um dos principais fatores que pode interferir no seu rendimento (AZEVEDO et al., 2011). O conhecimento da necessidade hídrica da cultura é de grande importância para o manejo adequado desta, bem como o entendimento da relação entre o consumo de água e a produtividade (NASCIMENTO, PEDROSA e TAVARES SOBRINHO, 2004).

Além da reposição hídrica adequada também é imprescindível à realização de um manejo eficiente de nutrientes, para satisfazer as necessidades da cultura. Para suprir essa necessidade, o uso de adubos orgânicos como o biofertilizante pode ser uma ótima alternativa para o produtor, pois a matéria orgânica além de fornecer nutrientes, melhora as características físico-químicas do solo, principalmente com relação ao aumento na capacidade de retenção de água (SILVA et al., 2011; SILVA et al., 2012).

O biofertilizante ainda promove ajustamento osmótico nas plantas e melhores condições para a emergência, crescimento e produtividade das culturas em condições adversas (SILVA et al., 2013). Além disso, permiti que as plantas desenvolvam o seu potencial genético e produtivo, proporciona maior absorção dos nutrientes necessários ao desenvolvimento vegetal, contribuindo para elevação da produtividade das culturas (OLIVEIRA et al., 2014).

Buscando melhores práticas de utilização de água, objetivou-se com essa pesquisa avaliar a produtividade da cultura do feijão-caupi sob diferentes lâminas de irrigação com uso de biofertilizante.

\section{MATERIAL E MÉTODOS}

O experimento foi conduzido entre outubro e dezembro de 2015, em uma área do Instituto Federal de Educação, Ciência e Tecnologia do Ceará (IFCE), no município de Umirim, CE, localizado nas coordenadas $3^{\circ} 41^{\prime} 09^{\prime \prime}$ de latitude Sul e 39'20'28' longitude Oeste, e altitude de 61 m. Segundo a classificação de Koppen o clima da região é considerado como $\mathrm{BSh}$, correspondendo ao clima semiárido com chuvas irregulares, apresentando dois períodos bem distintos (seco e chuvoso) (ALVARES et al., 2013). 
Para condução do trabalho foram coletados os dados climáticos de uma estação meteorológica automática do Instituto Nacional de Meteorologia - INMET, localizada no município de Itapipoca-CE. Os dados médios referentes ao período de realização do experimento estão apresentados na Tabela 1.

Tabela 1.Temperatura (Temp.) máxima (Máx), mínima (Min.) e média (Méd.); umidade relativa do ar (UR) máxima (Máx), mínima (Min.) e média (Méd.); radiação solar (RAD) e velocidade média do vento (Vmédia), medida durante a condução do experimento (07/10/2015 à 21/12/2015).

\begin{tabular}{|c|c|c|c|c|c|c|c|c|}
\hline \multirow{2}{*}{ Período } & \multicolumn{3}{|c|}{ Temp. média $\left({ }^{\circ} \mathrm{C}\right)$} & \multicolumn{3}{|c|}{ UR média (\%) } & \multirow{2}{*}{$\begin{array}{l}\text { RAD média } \\
\left(\mathrm{MJ} \mathrm{m}^{-2} \mathrm{dia}^{-1}\right)\end{array}$} & \multirow{2}{*}{$\begin{array}{l}\text { Vmédia } \\
\left(\mathrm{m} \mathrm{s}^{-1}\right)\end{array}$} \\
\hline & Máx. & Min. & Méd. & Máx. & Min. & Méd. & & \\
\hline Outubro & 35,6 & 24,9 & 28,3 & 74,3 & 30,8 & 58,1 & 23,2 & 4,21 \\
\hline Novembro & 35,3 & 25,2 & 28,5 & 76,5 & 32,6 & 59,9 & 22,5 & 4,15 \\
\hline Dezembro & 35,1 & 25,5 & 30,3 & 77,5 & 35,5 & 56,5 & 19,9 & 4,13 \\
\hline
\end{tabular}

Fonte: FUNCEME(2015).

Os dados meteorológicos foram utilizados no cálculo da evapotranspiração de referência diária (ETo), de acordo com a metodologia de Penman Monteith. Para determinação da evapotranspiração da cultura (ETc) utilizou-se a fórmula de Allen et al. (1998).

O solo da área é classificado como Argissolo Vermelho Amarelo distrófico (EMBRAPA, 2013), de textura franco argilo arenosa, apresentando respectivamente na camada arável (0-20) 238; 538 e $224 \mathrm{~g} \mathrm{~kg}^{-1}$ de argila, areia e de silte, $\mathrm{pH}\left(\mathrm{H}_{2} \mathrm{O}\right) 5,6 ; 1 \mathrm{mg} \mathrm{dm}^{-3}$ de $\mathrm{P}$ (Mehlich I); 3,6 mmolc $_{\mathrm{c}} \mathrm{dm}^{-3}$ de $\mathrm{K} ; 18$ mmolc $_{\mathrm{c}} \mathrm{dm}^{-3} \mathrm{de} \mathrm{Ca}^{2+}$; 12 mmol $_{\mathrm{c}} \mathrm{dm}^{-3}$ de $\mathrm{Mg}^{2+}$; 39,6 mmolc $_{\mathrm{c}} \mathrm{dm}^{-3} \mathrm{de}$ $\mathrm{H}+\mathrm{Al}$ e $16,96 \mathrm{~g} \mathrm{dm}^{-3}$ de matéria orgânica.

O delineamento experimental utilizado foi em bloco casualizados, distribuídos em esquema de parcelas subdivididas, com 8tratamentos e quatro repetições, totalizando 32 parcelas experimentais. As parcelas foram constituídas por quatro diferentes lâminas de irrigação (75\%, $100 \%, 125 \%$ e $150 \%$ da evapotranspiração da cultura - ETc). As subparcelas foram representadas pela ausência ou presença de biofertilizante líquido aplicado via solo, no volume de $15.000 \mathrm{~L} \mathrm{ha}^{-1}$.A cultivar de feijão-caupi utilizada foi a "BRS Pujante", pertencente ao grupo sempre verde e desenvolvida pela Embrapa Semiárido em Petrolina-PE. Ela apresenta elevada produtividade, tanto em sistema de sequeiro como irrigado, hábito de crescimento indeterminado, porte semi-ramador e primeira colheita aos 70 dias após a semeadura (DAS) (SANTOS, 2011).

Cada parcela experimental foi composta por cinco fileiras de feijão espaçadas a $0,4 \mathrm{~m}$, com cinco metros de comprimento e espaçamento entre plantas de 0,30 m, correspondendo a uma área de $10 \mathrm{~m}^{2}(5,0 \mathrm{~m} \times 2,0 \mathrm{~m})$ cada parcela. A área útil de cada parcela constitui-se das três fileiras centrais, descartando-se dois metros de cada uma das suas extremidades.

A irrigação foi realizada através de um sistema de gotejamento, utilizando-se uma fita gotejadora de polietileno, apresentando $0,30 \mathrm{~m}$ de distância entre gotejadores e vazão de $1,8 \mathrm{Lh}^{-1} \mathrm{sob}$ pressão de $1 \mathrm{kgf} \mathrm{cm}^{-2}$.

A água utilizada durante a irrigação foi oriunda de um poço profundo e suas características físico-químicas se encontram na Tabela 2.

Tabela 2. Análise físico-química da água de irrigação.

\begin{tabular}{|c|c|c|c|c|c|c|c|c|c|c|c|}
\hline \multirow[b]{2}{*}{$\mathrm{pH}$} & \multirow{2}{*}{$\frac{\mathrm{CE}}{\mathrm{dS} \mathrm{m^{-1 }}}$} & \multicolumn{4}{|c|}{---Cátions $\left(\right.$ mmol $\left._{\mathrm{c} .} \mathrm{L}^{-1}\right)---$} & \multicolumn{4}{|c|}{------ Ânions $\left(\mathrm{mmol}_{\mathrm{c}} \cdot \mathrm{L}^{-1}\right)$------- } & \multirow[b]{2}{*}{ RAS } & \multirow[b]{2}{*}{ Classificação* } \\
\hline & & $\mathrm{Ca}$ & $\mathrm{Mg}$ & $\mathrm{Na}$ & $\mathrm{K}$ & $\mathrm{Cl}^{-}$ & $\mathrm{SO}_{4}{ }^{2-}$ & $\mathrm{HCO}_{3-}$ & $\mathrm{CO}_{3}{ }^{2-}$ & & \\
\hline 6,4 & 3,81 & 12,6 & 17,2 & 6,4 & 2,1 & 35,0 & -- & 3,6 & -- & 1,65 & $\mathrm{C}_{4} \mathrm{~S}_{1}$ \\
\hline
\end{tabular}

$\mathrm{C}_{4}-$ Água de salinidade muito alta. Não é adequada para irrigação comum. Se, entretanto, culturas com uma tolerância muito alta ao sal forem cultivadas em solos altamente permeáveis e bem drenados. Caso seja utilizado um excesso de água de irrigação, a fim de prover uma copiosa lixiviação, o seu uso deve ser levado em consideração;

$\mathrm{S}_{1}-$ Água com baixo conteúdo de sódio. Pode ser usada para irrigação em quase todos os tipos de solos. Entretanto, certas culturas que são altamente sensíveis a sódio podem ser afetadas;

*Fonte:RICHARDS(1993). 
A frequência da irrigação foi diária, sendo que os tratamentos das lâminas começaram a ser aplicadas aos 8 DAS, quando já se obtinha um estante uniforme em todas as parcelas. $\mathrm{O}$ controle da lâmina aplicada foi realizado de acordo com $\mathrm{O}$ tempo em que o sistema de irrigação permaneceu ligado em cada parcela, seguindo a seguinte fórmula:

$\mathrm{TI}=\mathrm{LB} \times \mathrm{Eg} \times \mathrm{El} / \mathrm{qg}$

Em que:

TI: Tempo de irrigação (horas);

LB: Lâmina bruta;

Eg: Espaçamento entre gotejadores;

El: Espaçamento entre linhas;

$\mathrm{qg}_{\mathrm{g}}$ : vazão do gotejador $\left(\mathrm{L} \mathrm{h}^{-1}\right)$.

A aplicação das frações de $75,100,125$ e $150 \%$ da ETc resultou respectivamente nas seguintes lâminas totais de irrigação para a cultura do feijão-caupi: 406,27; 529,91; 653,6 e 777,22 mm. Ressalta-se que até 7 DAS foi aplicada a lâmina de $100 \%$ da ETc para todas as parcelas experimentais, sendo somente a partir do oitavo DAS iniciada a aplicação dos tratamentos. Durante o período experimental não houve a ocorrência de precipitação pluviométrica, de modo que a resposta produtiva ocorreu apenas em função das lâminas de irrigação aplicadas.

$\mathrm{O}$ biofertilizante utilizado durante $\mathrm{o}$ experimento foi obtido através de um processo de fermentação aeróbia, utilizando-se um recipiente com capacidade para 1000 litros, adicionando-se esterco bovino fresco de vacas estabuladas em plena lactação e água nas proporções de 1:1 (PENTEADO, 2007). Durante o período do seu preparo, foi realizada a homogeneização por agitação para melhor eficiência da fermentação.

Após decorridos 30 dias do processo de fermentação foi coletada uma amostra do biofertilizante e feita análise das suas características químicas (Tabela 3).

Tabela 3. Atributos físico-químicos do biofertilizante bovino líquido.

\begin{tabular}{|c|c|c|c|c|c|c|c|c|c|c|c|c|c|}
\hline $\mathrm{pH}$ & $\mathrm{CE}$ & M.O. & $\mathrm{N}$ & $\mathrm{P}_{2} \mathrm{O}_{5}$ & $\mathrm{~K}_{2} \mathrm{O}$ & $\mathrm{Ca}$ & $\mathrm{Mg}$ & S & $\mathrm{C} / \mathrm{N}$ & $\mathrm{Fe}$ & $\mathrm{Cu}$ & $\mathrm{Zn}$ & $\mathrm{Mn}$ \\
\hline- & $\mathrm{dS} \mathrm{m}^{-1}$ & -------- & - & ---- g & $-1-\cdots$ & ----- & ----- & & - & ---------- & $-\mathrm{mg} \mathrm{I}$ & - ----- & - \\
\hline 7,1 & 8,41 & 207,2 & 1,5 & 0,7 & 3,2 & 1 & 0,9 & - & 80,1 & 238,8 & 35,6 & 45,5 & 23,7 \\
\hline
\end{tabular}

CE - Condutividade elétrica; M.O. - Matéria orgânica.

Antes de aplicado no solo, o biofertilizante foi diluído em água em uma proporção de 1:1. Foram realizadas três aplicações do biofertilizante: A primeira foi realizada 10 DAS, a segunda 40 DAS e a terceira 70 DAS, sendo distribuído no solo, na área de projeção da copa das plantas.

Para avaliar a produtividade foram coletadas aos 75 DAS plantas da área útil de cada parcela experimental sendo posteriormente analisadas as seguintes variáveis: número de vagens por planta, comprimento e massa de vagem verde e seca, número de grãos por vagem, massa de grãos por vagem verde e seca, massa de 100 grãos verdes e secos e produtividade de grãos verdes e secos. Os valores de massa de grãos da cultura foram corrigidos para $13 \%$ de umidade.

Os resultados obtidos foram submetidos a análise de variância aplicando-se o teste F (5\% de significância),quando significativos as diferentes lâminas de irrigação foram analisadas por regressão e o uso de biofertilizante pelo teste de Tukey a $5 \%$ de probabilidade. Para todas as análises utilizou-se o software livre SISVAR versão 5.6 (FERREIRA, 2014).

\section{RESULTADOS E DISCUSSÃO}

O número de grãos por vagem respondeu aos efeitos da interação entre as lâminas de irrigação e a ausência/presença de biofertilizante, como indica a Tabela 4, da mesma forma que o comprimento médio de vagem seca respondeu isoladamente as diferentes lâminas de irrigação. $\mathrm{O}$ uso de biofertilizante não exerceu efeito significativo em nenhuma das variáveis analisadas, como indica a Tabela 4. 
Tabela 4. Número de vagens por planta (NVP), comprimento médio de vagem verde (CMVV) e seca (CMVS) e número de grãos por vagem (NGV) obtida de plantas de feijão-caupi irrigada com diferentes lâminas de água salina e com e sem uso de biofertilizante bovino.

\begin{tabular}{|c|c|c|c|c|c|}
\hline \multirow{2}{*}{$\mathrm{FV}$} & \multirow{2}{*}{ G L } & \multicolumn{4}{|c|}{ Quadrados médios } \\
\hline & & NVP & CMVV & CMVS & NGV \\
\hline Bloco & 3 & $3,08 \mathrm{~ns}$ & $26,36 \mathrm{~ns}$ & $2,62 \mathrm{~ns}$ & $5,32 \mathrm{~ns}$ \\
\hline Lâmina (L) & 3 & $2,4^{\mathrm{ns}}$ & $45,74^{\mathrm{ns}}$ & $63,76^{* *}$ & 16,43 ns \\
\hline Resíduo (L) & 9 & 2,37 & 16,67 & 4,02 & 6,11 \\
\hline Biofertilizante (B) & 1 & 0,06 ns & 59,41 ns & $2,16 \mathrm{~ns}$ & 0,01 ns \\
\hline $\mathrm{L} \times \mathrm{B}$ & 3 & $1,24^{\mathrm{ns}}$ & 33,79 ns & $4,96 \mathrm{~ns}$ & $12,27^{*}$ \\
\hline Resíduo (B) & 12 & 3,52 & 19,1 & 3,27 & 3,41 \\
\hline $\mathrm{CV} \%(\mathrm{~L})$ & - & 26,18 & 18,02 & 8,01 & 28,44 \\
\hline $\mathrm{CV} \%(\mathrm{~B})$ & - & 31,89 & 19,29 & 7,22 & 21,25 \\
\hline
\end{tabular}

FV - Fontes de Variação; CV - Coeficiente de Variação; GL - Graus de Liberdade; *Significativo pelo teste F a 5\%; ** Significativo pelo teste $\mathrm{F}$ a $1 \%$; ns= não significativo.

Observa-se na Figura 1 que equação de regressão se ajustou ao modelo quadrático, onde a lâmina de irrigação estimulou o aumento do comprimento médio de vagem verde, obtendo o valor máximo de $27,6 \mathrm{~cm}$ na lâmina máxima estimada de $118,7 \%$ da ET.

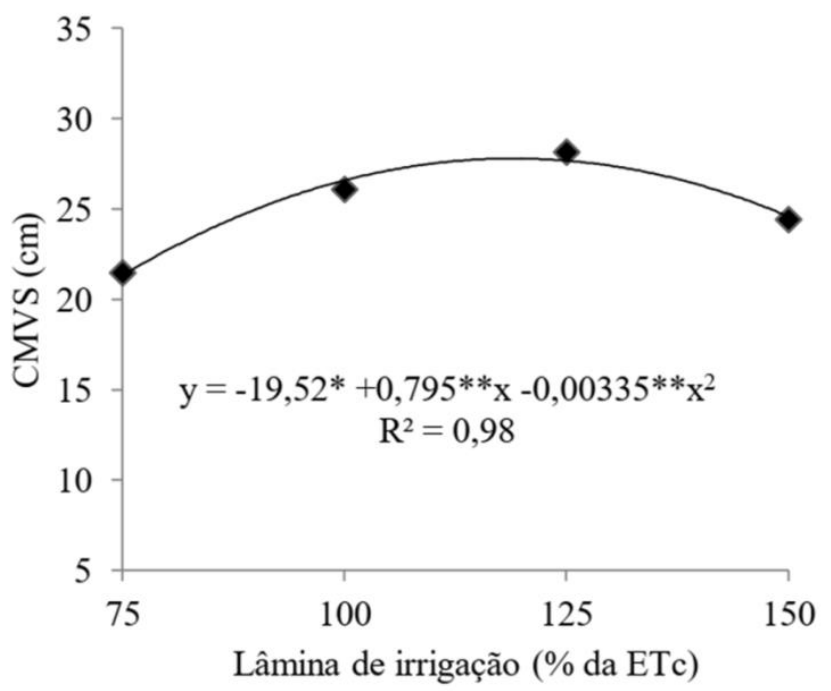

Figura 1. Comprimento médio de vagens secas (CMVS) de plantas de feijão-caupi em função da aplicação de diferentes lâminas de irrigação, UmirimCE, 2015.
*Significativo pelo teste $\mathrm{F}$ a $5 \%$; ** Significativo pelo teste $\mathrm{F}$ a $1 \%$ de probabilidade.

Moreira et al. (2015) aos avaliarem aspectos produtivos de feijão-caupi cv. Paulistinha, sob diferentes lâminas de irrigação, observaram crescimento linear para comprimento médio de vagem, obtendo valor máximo $(17,2 \mathrm{~cm})$ sob lâmina de $120 \%$ da ETc. Segundo os autores o comprimento médio de vagem tem relação com o número de grãos por vagem, tendo em vista que dependendo da severidade do estresse a planta pode direcionar suas reservar buscando aumentar a qualidade dos grãos.

Analisando a interação entre lâmina de irrigação e uso do biofertilizante sob o número médio de grãos por vagem (NGV), nota-se que a equação de regressão se ajustou ao modelo linear (Figura 2A), atingindo valor máximo estimado de 10,9 grãos por vagem sob a maior lâmina aplicada (150\% da ETc). O déficit hídrico pode afetar negativamente a cultura durante todo ciclo produtivo, sendo que durante a fase reprodutiva ela pode provocar baixo número de grãos por vagem, devido redução na taxa de polinização (SILVEIRA e STONE, 2001). 

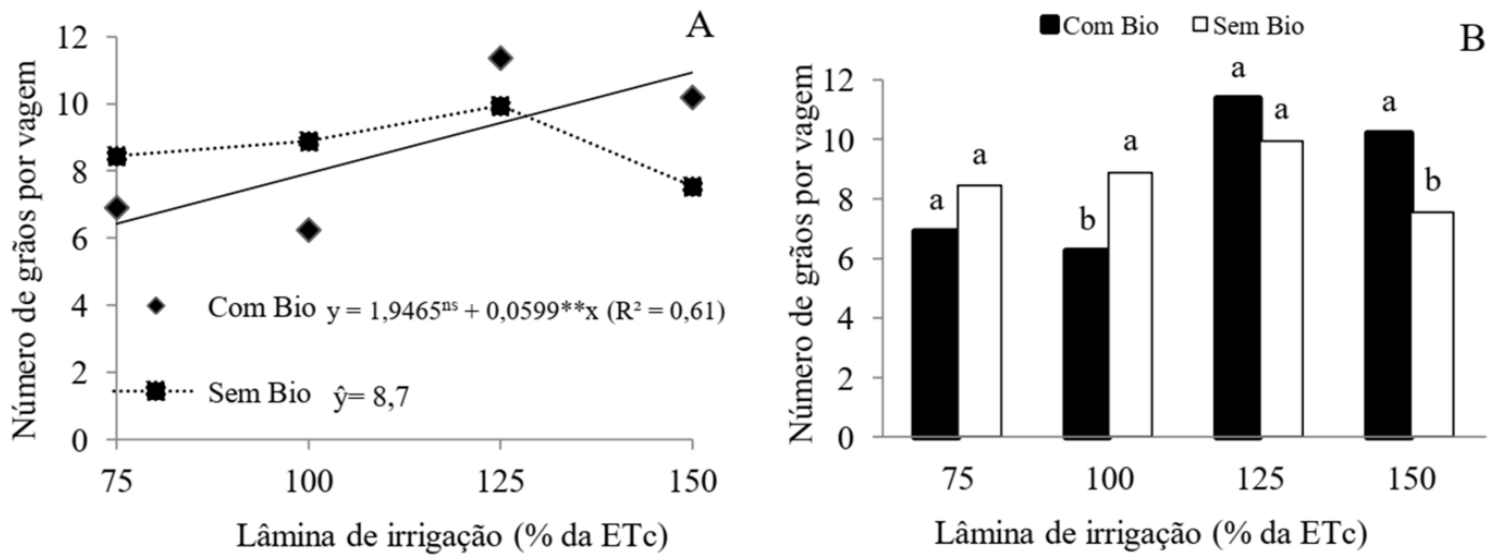

Figura 2. Interação entre as diferentes lâminas de irrigação versus a aplicação de biofertilizante sob o número de grãos por vagem em plantas de feijão-caupi, Umirim-CE, 2015.

${ }^{n s}$ Não significativo; ** Significativo pelo teste $\mathrm{F}$ a $1 \%$ de probabilidade. Médias seguidas pela mesma letra não diferem entre si pelo teste de Tukey (5\%).

Azevedo et al. (2011) ao conduzirem a cultura do feijão-caupi sob diferentes lâminas de irrigação, observaram variação NGV em função da quantidade de água aplicada, apresentando valores menores sob déficit e excesso de água aplicada. Nascimento, Pedrosa e Tavares Sobrinho (2004) obtiveram decréscimos de até $22 \%$ para o número de grãos por vagem, quando reduzida em $60 \%$ o volume de água aplicado.

Na Figura 2B observa-se o desdobramento da aplicação de biofertilizante dentro de cada lâmina de irrigação, onde observa-se diferença significativa entre a ausência e presença de biofertilizante sob as lâminas de 100 e $150 \%$ da ETc. Sob a lâmina de $100 \%$ da ETc a aplicação de biofertilizante proporcionou menor número de grãos por vagem. Resultado diferente foi obtido sob a lâmina de $150 \%$ da ETc em que o uso de biofertilizante, resultou em um maior número de grãos por vagem.

$\mathrm{Na}$ Tabela 5 nota-se que a interação entre as lâminas de irrigação e o uso de biofertilizante exerceu efeitos significativos sobre a massa de grãos verdes por vagem e massa de cem grãos. O uso de biofertilizante influenciou isoladamente a massa de cem grãos de forma significativa. A aplicação de diferentes lâminas de irrigação teve efeito significativo para a maioria das variáveis analisadas, exceto para a produtividade de grãos verdes.

Tabela 5. Massa de vagem verde (MVV), massa de grãos verdes por vagem (MGVV), massa de cem grãos verdes (M100GV) e produtividade de grãos verde (PGV) obtida de plantas de feijão-caupi irrigada com diferentes lâminas de água salina e com e sem uso de biofertilizante bovino.

\begin{tabular}{lccrrr}
\hline \multirow{2}{*}{ FV } & \multirow{2}{*}{ GL } & \multicolumn{5}{c}{ Quadrados médios } \\
\cline { 3 - 6 } & & MVV & MGVV & M100GV & \multicolumn{1}{c}{ PGV } \\
\hline Bloco & 3 & $1,34^{\mathrm{ns}}$ & $0,51^{\mathrm{ns}}$ & $35,86^{\mathrm{ns}}$ & $1.643 .302,84^{\mathrm{ns}}$ \\
Lâmina (L) & 3 & $12,09^{*}$ & $5,87^{* *}$ & $388,58^{* *}$ & $1.866 .463,45^{\mathrm{ns}}$ \\
Resíduo (L) & 9 & $2,58^{\mathrm{n}}$ & $0,83^{\mathrm{n}}$ & $14,23^{*}$ & $576.611,044^{\mathrm{ns}}$ \\
Biofertilizante (B) & 1 & $1,41^{\mathrm{ns}}$ & $0,49^{\mathrm{ns}}$ & $40,13^{*}$ & $188.181,77^{\mathrm{n}^{*}}$ \\
Lx B & 3 & $8,31^{\mathrm{ns}}$ & $5,83^{*}$ & $129,33^{* *}$ & $2.207 .852,34^{\mathrm{ns}}$ \\
Resíduo (B) & 12 & 5,25 & 1,05 & 6,69 & $1.101 .080,37$ \\
\hline CV\% (L) & - & 16,03 & 15,76 & 6,97 & 37,15 \\
CV\% (B) & - & 22,86 & 17,76 & 4,78 & 37,52 \\
\hline
\end{tabular}

FV - Fontes de Variação; CV - Coeficiente de Variação; GL - Graus de Liberdade; *Significativo pelo teste F a 5\%; ** Significativo pelo teste $\mathrm{F}$ a $1 \%$; ns= não significativo. 
Observa-se na Figura 3 o efeito da lâmina de irrigação sob a massa de vagem verde de plantas de feijão-caupi, proporcionou incremento do seu valor até a lâmina estimada de $112,6 \%$ da ETc obteve-se o valor máximo de $11,3 \mathrm{~g}$, seguido de redução até a máxima lâmina aplicada $(150 \%$ da ETc).

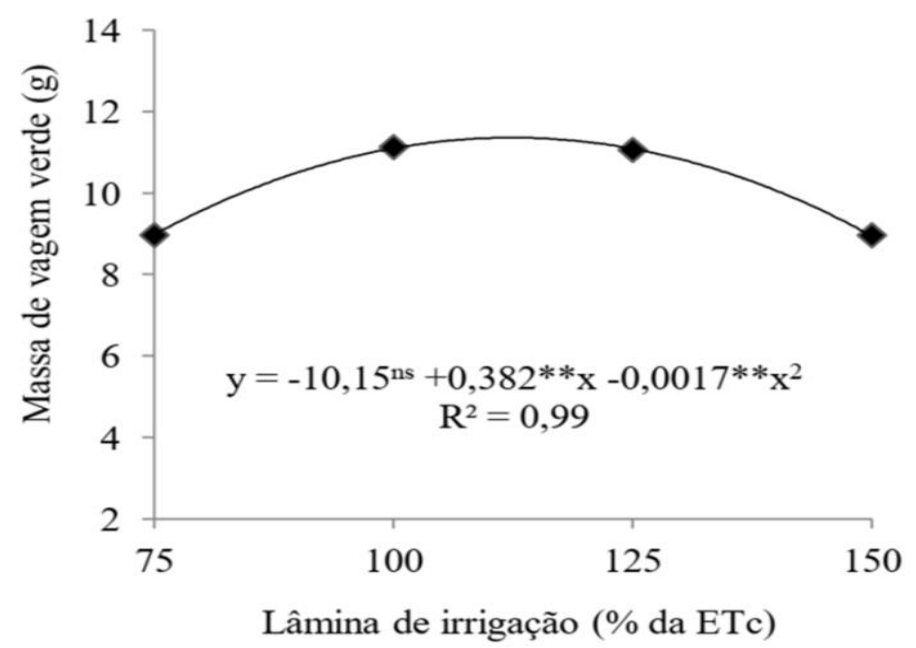

Figura 3. Massa de vagem verde de plantas de feijão-caupi em função da aplicação de diferentes lâminas de irrigação, Umirim-CE, 2015.

${ }^{\mathrm{n}}$ Não significativo; ** Significativo pelo teste $\mathrm{F}$ a $1 \%$ de probabilidade.

Para a massa de grãos verdes por vagem (Figura 4A), nota-se que o aumento do volume de água até a lâmina máxima aplicada, proporcionou um incremento de $45,63 \%$, atingindo uma massa $7,21 \mathrm{~g}$ na presença do biofertilizante $\left(15.000 \mathrm{~L} \mathrm{ha}^{-}\right.$ $1)$.
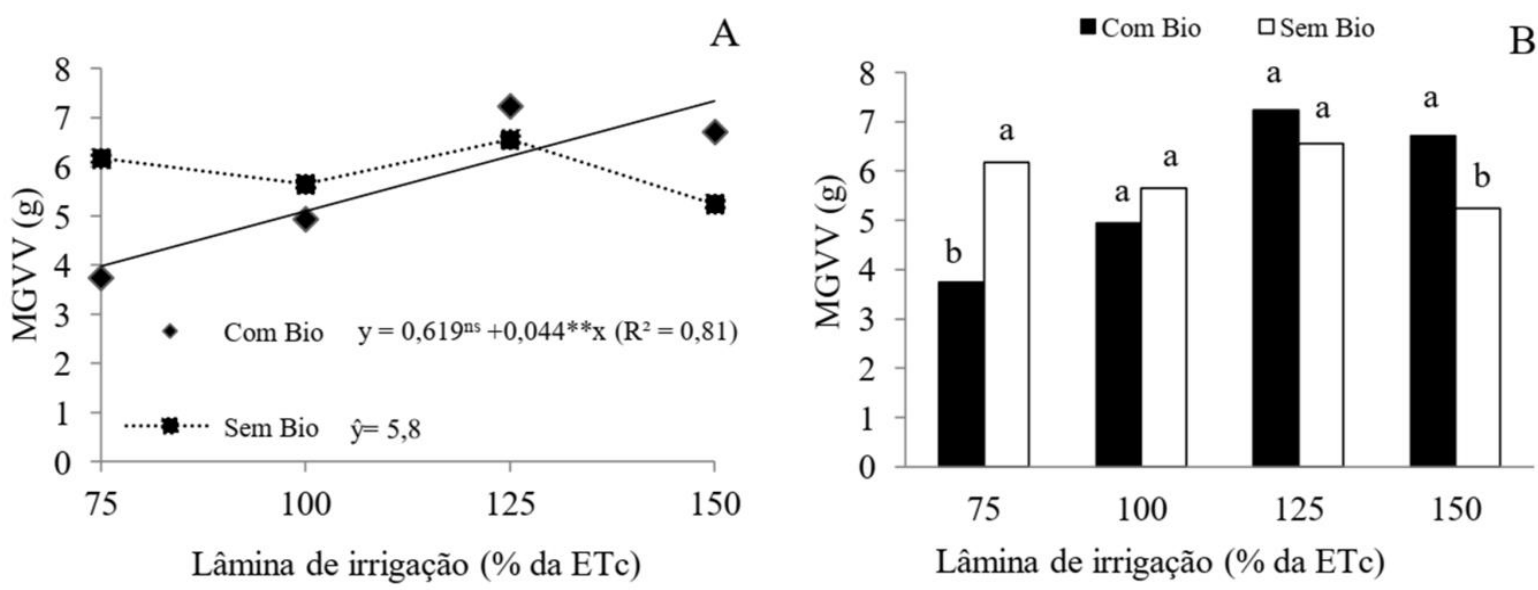

Figura 4. Desdobramento da interação entre as diferentes lâminas de irrigação versus a aplicação de biofertilizante sob a massa de grãos verdes por vagem (MGVV) em plantas de feijão-caupi, Umirim-CE, 2015.

${ }^{n}$ Não significativo; $* *$ Significativo pelo teste $\mathrm{F}$ a $1 \%$ de probabilidade. Médias seguidas pela mesma letra não diferem entre si pelo teste de Tukey (5\%).

Na Figura 4B observa-se o efeito do uso de biofertilizante dentro de cada lâmina de irrigação, que sob a lâmina de $75 \%$ da ETc a ausência de biofertilizante apresentou valores superiores, diferindo estatisticamente dos demais. Diferente do observado sob a lâmina de $150 \%$ da ETc onde a aplicação de biofertilizante proporcionou média superior. A elevada condutividade elétrica $(8,41$ $\mathrm{dS} \mathrm{m}^{-1}$ ) do biofertilizante (Tabela 3 ) pode ter acentuado o estresse hídrico nas plantas de feijãocaupi e assim interferindo no enchimento dos grãos. Respostas esta não observado sob a lâmina 
de $150 \%$ da ETc onde o volume de água aplicado, deve ter diminuído a CE do biofertilizante, possibilitando que a planta absorvesse água e nutrientes, desempenhando suas atividades fisiológicas normalmente.

Ressalta-se também que o biofertilizante é um produto obtido da fermentação aeróbica e/ou anaeróbica de materiais orgânicos, devido ser um adubo orgânico rico em macro e micronutrientes é considerado como uma ótima alternativa na nutrição de plantas. Entretanto devido não haver um controle quanto a quantidade de nutrientes, o excesso de algumas substâncias pode provocar efeitos indesejados nas plantas (ALVES et al., 2009). Para a massa de 100 grãos verdes (Figura $5 \mathrm{~A}$ ), observa-se que a equação de regressão ajustou-se ao modelo quadrático na presença de biofertilizante.
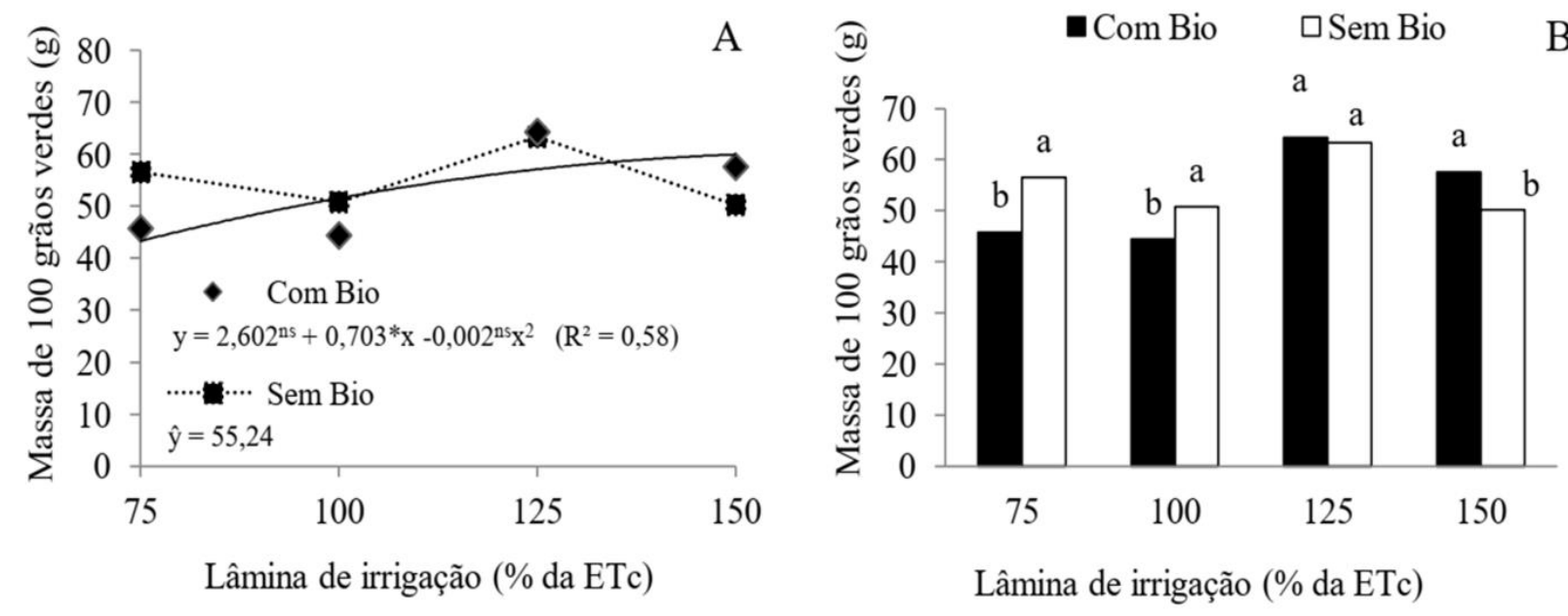

Figura 5. Desdobramento da interação entre as diferentes lâminas de irrigação versus a aplicação de biofertilizante sob a massa de cem grãos verdes em plantas de feijão-caupi, Umirim-CE, 2015.

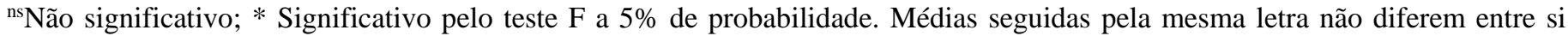
pelo teste de Tukey $(5 \%)$.

A fotossíntese é um dos principais processos interrompidos, acarretando diminuição na produção de fotoassimilados. Entretanto, em algumas espécies vegetais uma fração dos centros de reação do fotossistema II permanecem abertos e continuam realizando o trabalho fotoquímico, sem contudo provocar alterações significativas nas trocas gasosas (TEZARA, DRISCOLL e LAWLOR, 2008). Estes resultados levam a crer que a cultura do feijão-caupi pode também ter adotado está estratégia visando aumentar sua tolerância diante das condições de déficit hídrico.

Na Figura 5B observamos o desdobramento do uso de biofertilizante dentro de cada lâmina de irrigação sob a massa de cem grãos verdes, sendo que sob a lâmina de 75 e $100 \%$ da ETc obtemos uma diferença respectiva de 19,22 e $12,6 \%$. Santana et al. (2012) ressaltam que a matéria orgânica resulta em muitos efeitos benéficos ao solo, tais como melhoria nas das suas propriedades biológicas, físicas e químicas, aumentando assim o fornecimento de nutrientes às plantas e favorecendo seu crescimento e produtividade. Entretanto, dependendo da composição química, taxa de mineralização e teor de nutrientes podem tornar-se prejudiciais às culturas (FIGUEIREDO et al., 2012).

Na Tabela 6 observa-se que a interação entre as lâminas de irrigação e o uso de biofertilizante exerceu efeito significativo sobre a massa de grãos secos por vagem.

As diferentes lâminas de irrigação apresentaram efeito significativo sobre todas as variáveis analisadas, diferente do uso de biofertilizante que isoladamente não influenciou significativamente nenhuma variável.

Tabela 6. Massa de vagem seca (MVS), massa de grãos secos por vagem (MGSV), massa de cem grãos secos (M100GS) e produtividade de grãos secos (PGS) obtida de plantas de feijão-caupi irrigada com diferentes lâminas de água salina e com e sem uso de biofertilizante bovino. 


\begin{tabular}{|c|c|c|c|c|c|}
\hline \multirow{2}{*}{ F.V. } & \multirow{2}{*}{ G. L. } & \multicolumn{4}{|c|}{ Quadrados médios } \\
\hline & & MVS & MGSV & M100GS & PGS \\
\hline Bloco & 3 & $0,65 \mathrm{~ns}$ & $0,54^{*}$ & $11,99 \mathrm{~ns}$ & $378.265,6 \mathrm{~ns}$ \\
\hline Lâmina (L) & 3 & $4,78^{* *}$ & $6,85^{* *}$ & $124,84 *$ & $2.178 .151,2^{* *}$ \\
\hline Resíduo (L) & 9 & 0,22 & 0,11 & 21,12 & $230.047,66$ \\
\hline Biofertilizante (B) & 1 & $0,09 \mathrm{~ns}$ & $0,3 \mathrm{~ns}$ & $10,93 \mathrm{~ns}$ & $149.442,77 \mathrm{~ns}$ \\
\hline$L \times B$ & 3 & $0,24 \mathrm{~ns}$ & $0,87^{*}$ & $24,14 \mathrm{~ns}$ & $678.181,74 \mathrm{~ns}$ \\
\hline Resíduo (B) & 12 & 0,43 & 0,17 & 10,18 & $420.331,55$ \\
\hline CV\% (L) & - & 9,24 & 7,65 & 13,07 & 23,53 \\
\hline CV\% (B) & - & 12,71 & 9,84 & 9,08 & 31,81 \\
\hline
\end{tabular}

F.V. - Fontes de Variação; C.V. - Coeficiente de Variação; G.L. - Graus de Liberdade; *Significativo pelo teste F a 5\%; ** Significativo pelo teste $\mathrm{F}$ a $1 \%$; ns= não significativo.

O aumento da lâmina de irrigação proporcionou incremento para a massa de vagem seca (Figura 6), atingindo valor máximo de $5,9 \mathrm{~g}$ sob a lâmina de $120,8 \%$ da ETc, seguido de um decréscimo de $9,92 \%$ até a lâmina máxima aplicada (150\% da ETc).

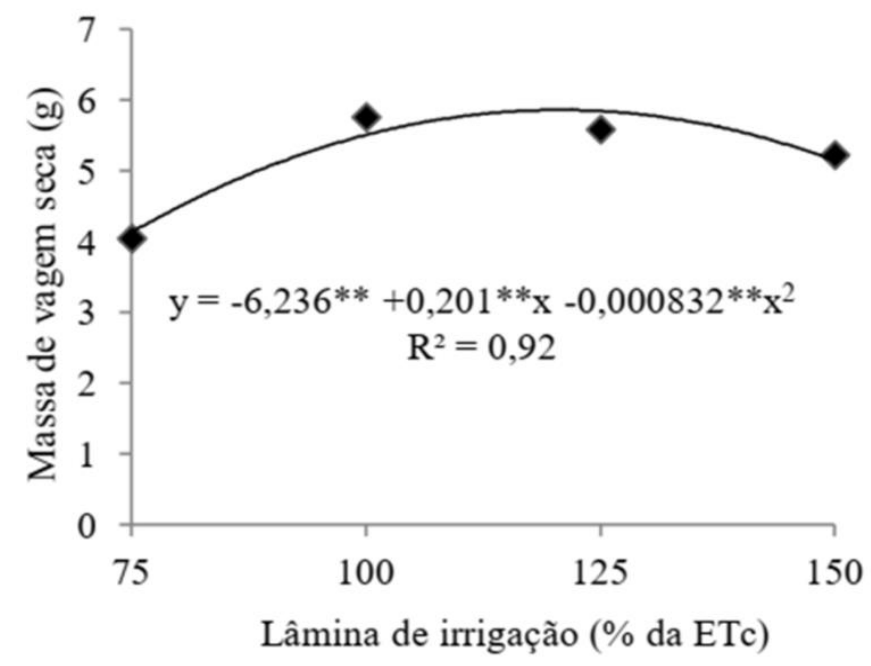

Figura 6. Massa de vagem seca de plantas de feijãocaupi em função da aplicação de diferentes lâminas de irrigação, Umirim-CE, 2015.

** Significativo pelo teste $\mathrm{F}$ a $1 \%$ de probabilidade.

No desdobramento da lâmina de irrigação na ausência e presencia de biofertilizante para a massa de grãos secos por vagem (Figura 7A), nota-se que em ambas situações as equações de regressão se ajustarem ao modelo quadrático. Com aplicação de biofertilizante o maior valor obtido foi $5,28 \mathrm{~g}$ sob a lâmina estimada de $113,06 \%$ da ETc, já da ausência obtevese a massa de $4,55 \mathrm{~g}$ sob a lâmina estimada de 121,0\% da ETc. Bezerra et al., (2003) considera o período de enchimento dos grãos como a fase mais crítica para as culturas, pois dependendo da severidade pode provocar perdas significativas na qualidade dos grãos e produtividade. 

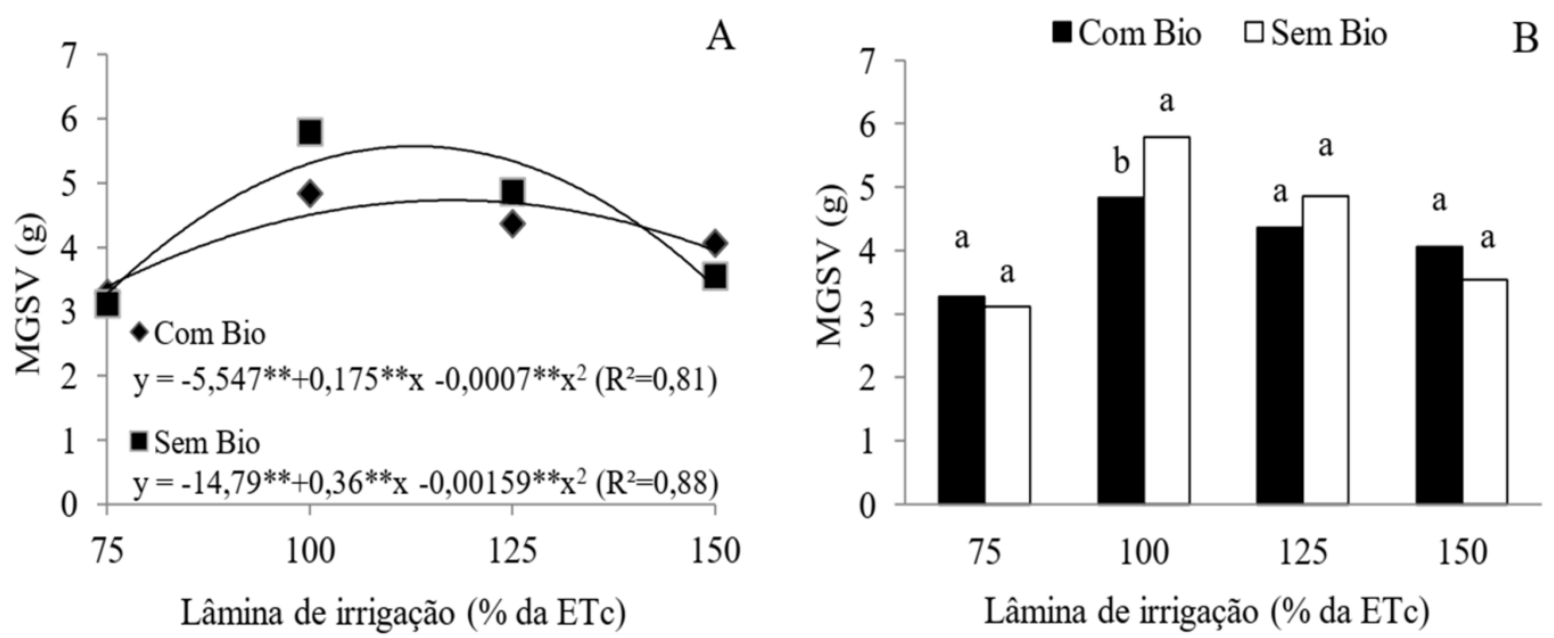

Figura 7. Desdobramento da interação entre as diferentes lâminas de irrigação versus a aplicação de biofertilizante sob a massa de grãos secos por vagem (MGSV) em plantas de feijão-caupi, Umirim-CE, 2015.

** Significativo pelo teste $\mathrm{F}$ a $1 \%$ de probabilidade. Médias seguidas pela mesma letra não diferem entre si pelo teste de Tukey $(5 \%)$.

Na figura 7B observa-se o desdobramento do uso de biofertilizante em cada lâmina de irrigação, em que sob a lâmina de $100 \%$ da ETc observamos maior média sem o uso de biofertilizante. Para massa de cem grãos e produtividade de grãos secos (Figura 8) observa- se o efeito da lâmina de irrigação em que a equação de regressão se ajustou ao modelo quadrático, apresentando respectivamente valor máximo sob as lâminas estimadas de 107,6 e $118,7 \%$ da ETc, equivalendo a 38,7 g e $2.498,88$ $\mathrm{Kg} \mathrm{ha}^{-1}$.
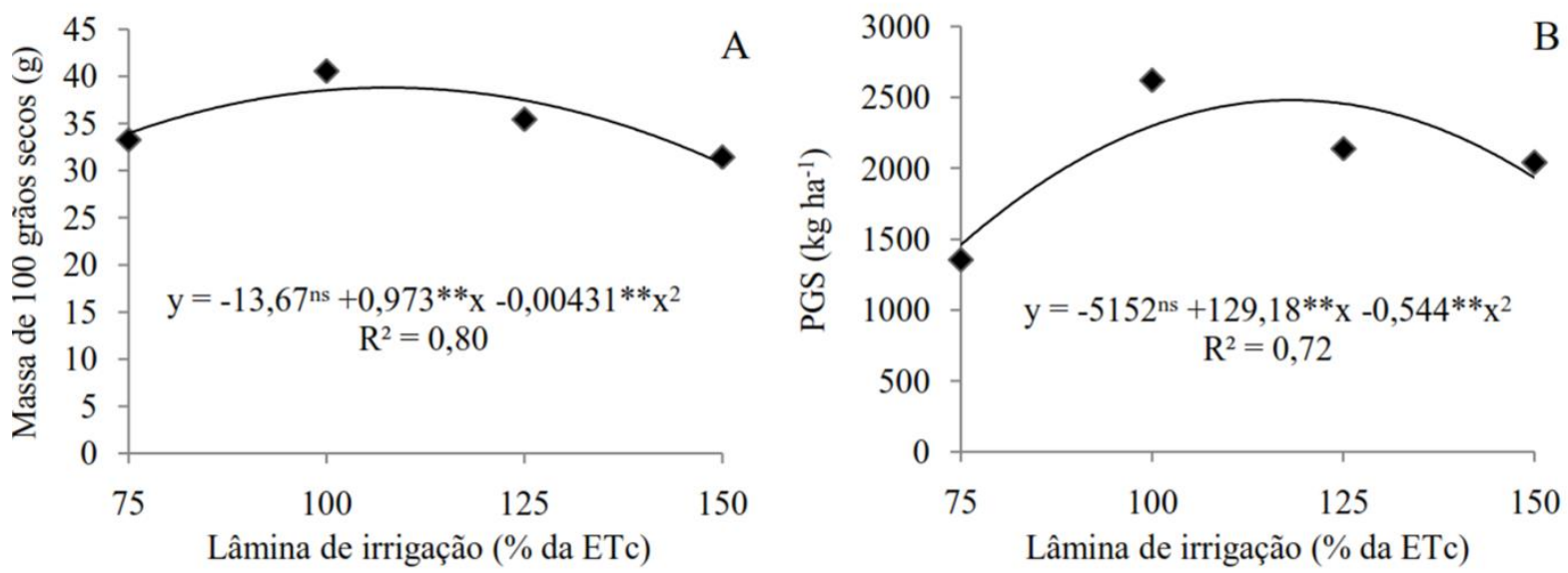

Figura 8. Massa de cem grãos (A) e produtividade de grãos secos (PGS) (B) de plantas de feijão-caupi em função da aplicação de diferentes lâminas de irrigação, Umirim-CE, 2015.

${ }^{n s}$ Não significativo; ${ }^{*}$ Significativo pelo teste $\mathrm{F}$ a $1 \%$ de probabilidade. Médias seguidas pela mesma letra não diferem entre si pelo teste de Tukey (5\%).

Lâminas acima desses valores (107,6 e 118,7\% da ETc) provocaram redução dos valores das variáveis analisadas, sendo que para produtividade obtemos $1.465,5$ e $1.985 \mathrm{Kg} \mathrm{ha}^{-1}$ sob a lâmina mínima e máxima aplicada. Esses valores representam respectivamente uma redução de 41,35 e $20,56 \%$ se comparada a máxima produtividade estimada.
Quando exposta a condição de déficit hídrico, a planta sofre redução da condutância e da transpiração foliar e, como consequência há um aumento da temperatura foliar e redução na produção de fotoassimilados, causando redução na produtividade de grãos (TAIZ et al., 2017). Enquanto que o excesso de água, provavelmente provocou a deficiência de oxigênio no solo, o que reduz a atividade microbiana no solo, e assim 
promovendo redução da produtividade (TORRES et al., 2013). Azevedo et al. (2011) obtiveram uma produtividade máxima de $2.190 \mathrm{~kg} \mathrm{ha}^{-1}$ quando aplicada uma lâmina estimada de $592 \mathrm{~mm}$.

\section{CONCLUSÕES}

Aplicação de lâminas acima de $125 \%$ da ETc provoca redução nos componentes produtivos e produtividade do feijão-caupi.

O uso de biofertilizante associado com lâminas de 75 e 100\% da evapotranspiração da cultura reduz os valores dos componentes produtivos da cultura do feijão-caupi.

Aplicação de biofertilizante com uma lâmina de $150 \%$ da evapotranspiração da cultura proporciona aumento na massa de grãos na cultura do feijão-caupi.

\section{REFERÊNCIAS}

ALLEN, R.G.; PEREIRA, L. S.; RAES, D.; SMITH, M. Crop evapotranspiration: guidelines for computing crop water requirements. Rome: FAO, 1998. 279p.

ALVARES, C. A.; STAPE, J. L.; SENTELHAS, P. C.; GONÇALVES, J. L. de M.; SPAROVEK, G. Köppen's climate classification map for Brazil. Meteorologische Zeitschrift, v. 22, n. 6, p. 711728, 2013. DOI: http://dx.doi.org/10.1127/09412948/2013/0507

ALVES, S. V.; ALVES, S. S. V.; CAVALCANTE, M. L. F.; DEMARTELAERE, A. C. F.; LOPES, W. de A. R. Produção de feijão caupi em função de diferentes dosagens e concentração de biofertilizantes. Revista verde de agroecologia e desenvolvimento sustentável, v. 4, n. 3, p. 45-49, 2009.

AZEVEDO, B. M.; FERNANDES, C. N. V.; PINHEIRO, J. A.; BRAGA, E. S.; VIANA, T. V. de A.; CAMBOIM NETO, L de F.; MARINHO, A. B. Efeitos de lâminas de irrigação na cultura do feijão vigna de cor preta. Agropecuária técnica, v. 32, n. 1, p. $152-159,2011$. DOI: http://dx.doi.org/10.25066/agrotec.v32i1.9801
BEZERRA, F. M. L.; ARARIPE, M. A. E.; TEÓFILO, E. M.; CORDEIRO, L. G.; SANTOS, J. J. A. Cowpea submitted to water deficit in different growth periods. Revista Ciência Agronômica, v. 34, n. 1, p. 5-10, 2003.

EMBRAPA. Sistema brasileiro de classificação de solos.3.ed. Brasília: Embrapa, 2013. 353p.

FERREIRA, D. F. Sisvar: a guide for its bootstrap procedures in multiple comparisons. Ciencia e Agrotecnologia, v. 38, n. 2, p. 109-112, 2014. DOI: $\quad$ http://dx.doi.org/10.1590/S141370542014000200001

FIGUEIREDO, C. C. de; RAMOS, M. L. G.; MCMANUS, C. M.; MENEZES, A. M. de. Mineralização de esterco de ovinos e sua influência na produção de alface. Horticultura Brasileira, v. 30, n. 1, p. 175-179, 2012.

FREIRE FILHO, F. R. Feijão-Caupi no Brasil: Produção, melhoramento genético, avanços e desafios. Piauí: Embrapa Meio Norte, 2011. 80p.

FUNCEME. Calendário das chuvas no Estado do Ceará. 2015.Disponível em: http://www.funceme.br/index.php/areas/23monitoramento/meteorol\%C3\%B3gico/406chuvas-di\%C3\%A1rias. Acesso em: 21dez.2015.

MOREIRA, R. C. L.; BRITO, M. E. B.; SILVA, L. de A.; FRADE, L. J. G.; OLIVEIRA, I. M. de.; FERNANDES, P. D. Aspectos produtivos de grãos secos de feijão caupi, cv. paulistinha, sob lâminas de irrigação. In: INOVAGRI INTERNATIONAL MEETING, 3., Fortaleza. Anais... Fortaleza: INOVAGRI, 2015. p. 2495-2502. http://dx.doi.org/10.12702/iii.inovagri.2015-a269.

NASCIMENTO, J. T.; PEDROSA, M. B.; TAVARES SOBRINHO, J. Efeito da variação de níveis de água disponível no solo sobre o crescimento e produção de feijão caupi, vagens e grãos verdes. Horticultura Brasileira, v. 22, n. 2, p. 174-177, 2004.

OLIVEIRA, F. J.; ANUNCIAÇÃO FILHO, C. J. da ; BASTOS, G. Q.; REIS, O. V. dos.; 
TEÓFILO, E. M. Caracteres agronômicos aplicados na seleção de cultivares de caupi. Revista Ciência Agronômica, v. 34, n. 1, p. 511, 2003.

OLIVEIRA, J. R.; GOMES, R. L.; ARAÚJO, A. S.; MARINI, F. S.; LOPES, J. B.; ARAÚJO, R. M. Estado nutricional e produção da pimenteira com uso de biofertilizantes líquidos. Revista Brasileira de Engenharia Agrícola e Ambiental, v. 18, n. 12, p. 1241-1246, 2014. DOI: $\quad$ http://dx.doi.org/10.1590/18071929/agriambi.v18n12p1241-1246

PENTEADO, S. R. Adubação Orgânica: Compostos orgânicos e biofertilizantes. 2. ed. Campinas: Edição do autor, 2007.162 p.

RICHARDS, L. A. Diagnóstico y recuperción de suelos salinos y sódicos:Personal de Laboratório de Salinidade EE.UU. 6. Ed. México: Editorial LIMUSA. 1993. 176p.

SALVADOR, C. A. Feijão. Secretaria da Agricultura e do Abastecimento, n. 41, p. 1-15, 2010.

SANTANA, C. T. C.; SANTI, A.; DALLACORT, R.; SANTOS, M. L.; MENEZES, C. B. da . Desempenho de cultivares de alface americana em resposta a diferentes doses de torta de filtro. Revista Ciencia Agronomica, v. 43, n. 1, p. 2229, 2012.

SANTOS, C. A. F. Cultivares de feijão-caupi para o Vale do São Francisco. Circular técnica, n. 94, p. 1-10, 2011.

SILVA, F. L. B.; LACERDA, C. F.; SOUSA, G. G.; NEVES, A. L. R.; SILVA, G. L.; SOUSA, C. H. C. Interação entre salinidade e biofertilizante bovino na cultura do feijão-de-corda. Revista Brasileira de Engenharia Agrícola e Ambiental, v. 15, n. 4, p. 383-389, 2011.

SILVA, M. L. N.; OLIVEIRA, F. D. A.; OLIVEIRA, M. K. T.; MAIA, P. D. M. E.; SILVA, R. C. P.; SILVA, O. M. D. P. Efeito de biofertilizante bovino aeróbico na cultura do feijão caupi. Agropecuária científica no semiárido, v. 9, n. 1, p. 110-116, 2013.

SILVA, J. A.; OLIVEIRA, A. P.; ALVES, G. D. S.; CAVALCANTE, L. F.; OLIVEIRA, A. N. P. de; ARAÚJO, M. A. M. Rendimento do inhame adubado com esterco bovino e biofertilizante no solo e na folha. Revista Brasileira de Engenharia Agrícola e Ambiental, v. 16, n. 3, p. 253-257, 2012.

SILVEIRA, P. M.; STONE, L. F. Irrigação do feijoeiro. Santo Antonio do Goiás, Embrapa, 2001, 228 p.

TAIZ, L.; ZEIGER, E.; MULLER, I. M.; MURPHY, A.Fisiologia e Desenvolvimento Vegetal. 6. ed. Porto Alegre: ArtMed, 2017. 888 p..

TEZARA, W.; DRISCOLL, S.; LAWLOR, D. W. Partitioning of photosynthetic electron flow between $\mathrm{CO}_{2}$ assimilation and $\mathrm{O}_{2}$ reduction in sunflower plants under water deficit. Photosynthetica, v. 46, n. 1, p. 127-134, 2008.

TORRES, J. L. R.; SANTANA, M. J.; PIZOLATO NETO, A.; PEREIRA, M. G.; VIEIRA, D. M. da S. Produtividade de feijão sobre lâminas de irrigaçãoo e coberturas de solo. Bioscience Journal, v. 29, n. 4, p. 833-841, 2013. 